\title{
SYNTHESIS AND CHARACTERIZATION OF COPPER OXIDE NANOPARTICLES USING RAMBUTAN PEEL EXTRACT VIA GREENER ROUTE
}

\author{
L. Ragunath ${ }^{1}$, J. Suresh ${ }^{1, \bigotimes}$, M. Sankaran ${ }^{2}$, R. Suresh Kumar ${ }^{3}$, \\ A. I. Almansour ${ }^{3}$ and N. Arumugam ${ }^{3}$ \\ ${ }^{1}$ Department of Chemistry, Sri Ramakrishna Engineering College, N.G.G.O Colony, \\ Coimbatore-641 022, Tamil Nadu, India \\ ${ }^{2}$ Department of Chemistry, School of Sciences, Bharathiar University, \\ Coimbatore-641 046, Tamil Nadu \\ ${ }^{3}$ Department of Chemistry, College of Science, King Saud University, \\ P.O. Box 2455, Riyadh 11451, Saudi Arabia \\ ${ }^{\bowtie}$ Corresponding Author: suresh.j@srec.ac.in (Joghee Suresh)
}

\begin{abstract}
An efficient, greener, simple approach to synthesize copper oxide nanoparticles using aqueous extract of rambutan peel as a precipitant and reducing agent. Green synthesis of copper oxide nanoparticles was found via hydroxide precipitation using rambutan peel wastes. The successful formation of copper oxide nanoparticles was confirmed by UV-Visible, XRD, SEM, TEM and SAED studies. UV-Visible confirms the absorption spectrum of copper oxide around 360nm. X-Ray Diffraction results found the highest intense peak (111) and the average crystallite size calculated as $35.74 \mathrm{~nm}$ using debye scherrer's formula. Scanning Electron Microscopy (SEM) and Transmission Electron Microscopy (TEM) images confirm the formation of copper oxide nanoparticles looks flake-like structures and shows the particle size range between 20-50nm. Further Selected Area Electron Diffraction (SAED) pattern also confirms the crystalline nature of copper oxide nanoparticles. Further, a possible formation mechanism was proposed for $\mathrm{CuO}$ nanoparticles using rambutan peel wastes.
\end{abstract}

Keywords: Rambutan Peel, Copper Oxide, Biosynthesis, XRD, SEM, TEM

RASĀYAN J. Chem., Vol. 14, No.4, 2021

\section{INTRODUCTION}

Nowadays, we compare existing biological, physical and chemical methods, plant extract-based synthesis shows greener and eco-friendly alternative methods to synthesize biocompatible nanoparticles. ${ }^{1-3}$ Recently, synthetic strategies employing biological plant extract ${ }^{4-6}$, enzymes ${ }^{7}$ and microorganisms ${ }^{8}$ play a vital role in forming nanoparticles. Among the transition metal oxides, copper oxide nanoparticles have potential industrial applications in catalysis, sensors, biocidal activity and superconductivity. ${ }^{9-13}$ Various conventional methods are available for the synthesis of copper oxide nanoparticles. Some of them are sol-gel, chemical vapor deposition, precipitation, pyrolysis, sonochemistry, electrochemistry, one-step solid-state reactions, cathodic vacuum arc and solvothermal reactions. ${ }^{14-21}$ The above-said methods are expensive and environmentally hazardous and they can apply in biological and clinical applications. So due to environmental concerns, the green synthetic approach for the synthesis of nanomaterials is given more importance nowadays. The utilization of plants extracts, microorganisms, or plant biomass has been a recent research topic for the formation of nanoparticles over physical and chemical methods. ${ }^{22-24}$ Recently, many groups successful to synthesized nanoparticles using unicellular organisms and plant extracts such as neem leaves, lemongrass, geranium leaves, aloe vera etc., ${ }^{25-37}$ This new green chemistry approach is also in consequence with its simplicity, eco-friendly, inexpensive price and environmentally acceptable nature. In this present work, we choose rambutan fruit peels as one of the biological waste materials. We have to synthesize copper oxide nanoparticles and using the rambutan peel extract and it can be characterized by 
different techniques like UV - Visible, XRD, SEM and TEM analysis. To the best of our knowledge, it is the first report on the synthesis of $\mathrm{CuO}$ nanoparticles using rambutan fruit peel extract and no other attempts have been made earlier so far.

\section{EXPERIMENTAL}

\section{Materials}

The rambutan fruit peels were collected from a fruit stall at Coonoor, Tamil Nadu, India. $\mathrm{Cu}\left(\mathrm{SO}_{4}\right)_{2} .5 \mathrm{H}_{2} \mathrm{O}$, ethanol were purchased from Merck chemicals Ltd, India.

\section{Preparation of the Extract}

Rambutan fruit peels were separated manually and washed thoroughly with running water. Then it is cut into small pieces and then placed in a circulating oven for drying purposes. About $3 \mathrm{~g}$ of finely dried rambutan peels were boiled with a mixture of ethanol and double distilled water (1:2 ratio) for $10 \mathrm{~min}$. Then the obtained extract is filtered and collected in a $250 \mathrm{ml}$ flask and stored in the refrigerator.

\section{Synthesis of Copper Oxide Nanoparticles}

$0.1 \mathrm{M}$ of copper sulphate pentahydrate $\left(\mathrm{Cu}\left(\mathrm{SO}_{4}\right)_{2} .5 \mathrm{H}_{2} \mathrm{O}\right)$ was prepared in $50 \mathrm{~mL}$ double distilled water and add $10 \mathrm{~mL}$ of rambutan peel extract was added slowly. Then the mixture was kept under magnetic stirring at $80^{\circ} \mathrm{C}$ for two hours and it formed a copper hydroxide precursor. The light green precipitate is formed and then centrifugation for 15 minutes. Further, the separated light green precipitate dried in an oven for four hours, followed by grinding using mortar and pestle. Then finally, the powdered sample undergoes calcination around $450^{\circ} \mathrm{C}$ to get pure copper oxide nanoparticles.

\section{UV-Visible Absorbance Studies}

\section{RESULTS AND DISCUSSION}

Figure-1a and $\mathrm{b}$ show the UV-Vis spectra recorded for the pure natural extract and the synthesized copper oxide nanoparticles. The spectrum of pure extract does not show any characteristic absorption peak, which confirms organic compounds present in the rambutan peel extract. The UV-Visible absorption spectrum of $\mathrm{CuO}$ nanoparticles shows a broad absorption peak around $370 \mathrm{~nm}$. The obtained continuous rise from wavelength $600 \mathrm{~nm}$ confirms the characteristic optical absorption of $\mathrm{CuO}$ nanoparticles.

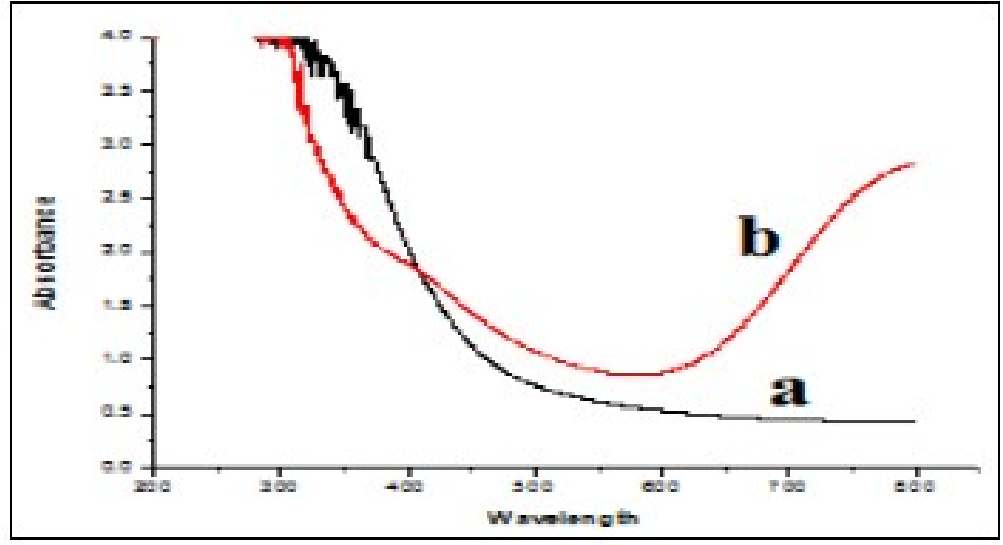

Fig.-1: UV Visible Spectrum of (a) Rambutan Extract, (b) Synthesized Copper Oxide Nanoparticles

\section{XRD Analysis}

Figure-2 shows the XRD spectrum of $\mathrm{CuO}$ nanoparticles and it's clearly observed the presence of sharp peaks as well as broad peaks suggesting the formation of the resulting $\mathrm{CuO}$ products were of mixed-phase of an amorphous and crystalline state. The diffraction peaks at $2 \theta=32.06^{\circ}, 35.48^{\circ}$, $38.74^{\circ}, 48.71^{\circ}, 61.53^{\circ}$ and $66.07^{\circ}$ are assigned to (110), (111), (200), (202), (113) and (311) crystal planes 
of cubic phase $\mathrm{CuO}$ and it match with JCPDS data card (89-2529). The crystallite size of the $\mathrm{CuO}$ nanocrystals was estimated from a higher intense peak of the XRD spectrum using Debye Scherrer's equation. The average crystallite size of the higher intense plane of (111) was $35.74 \mathrm{~nm}$.

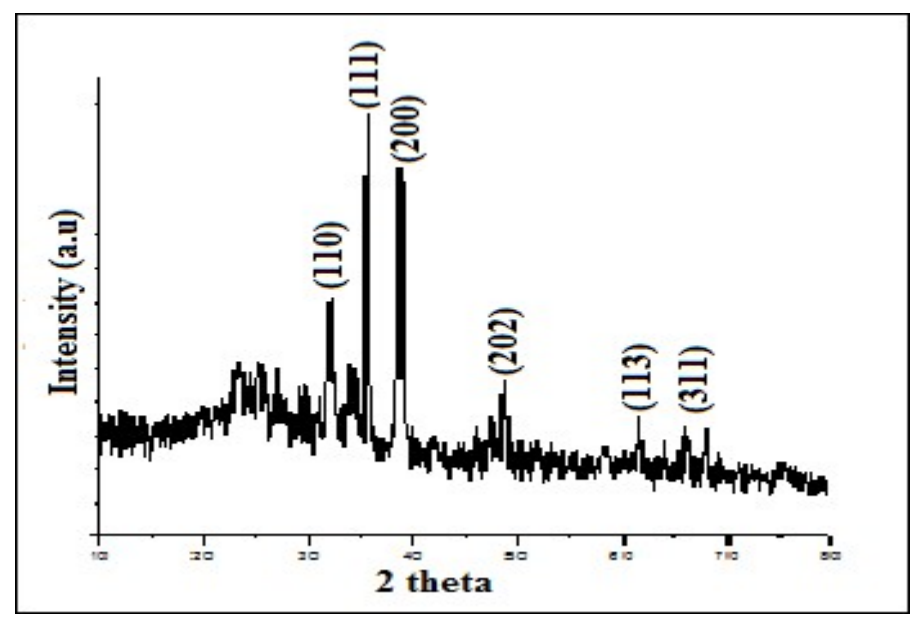

\section{SEM and TEM Analysis}

Fig.-2: X-ray Diffraction Pattern of Copper Oxide Nanoparticles

Figure-3 ( $a$ and $b$ ) shows the SEM image of copper oxide nanoparticles at different magnifications. The SEM images showed a flake-like structure and nanoparticles were distributed in the form of aggregation of small individual nanocrystallites of about $20-50 \mathrm{~nm}$ in size. Figure-4 (a and b) shows the representative TEM images of $\mathrm{CuO}$ nanoparticles. The uniform weak agglomeration of $\mathrm{CuO}$ nanoparticles with reasonable distribution has evidence from the obtained TEM images. The average crystallite size obtained from TEM images was around $40 \mathrm{~nm}$ which agrees well with the size calculated from XRD analysis. Figure-4c shows the electron diffraction (SAED) pattern of the selected area and its confirmed diffraction rings and hallow patterns, apparently indicating the obtained mixed phase of an amorphous and crystalline state of the Copper oxide grains, which is also evident from the XRD pattern.

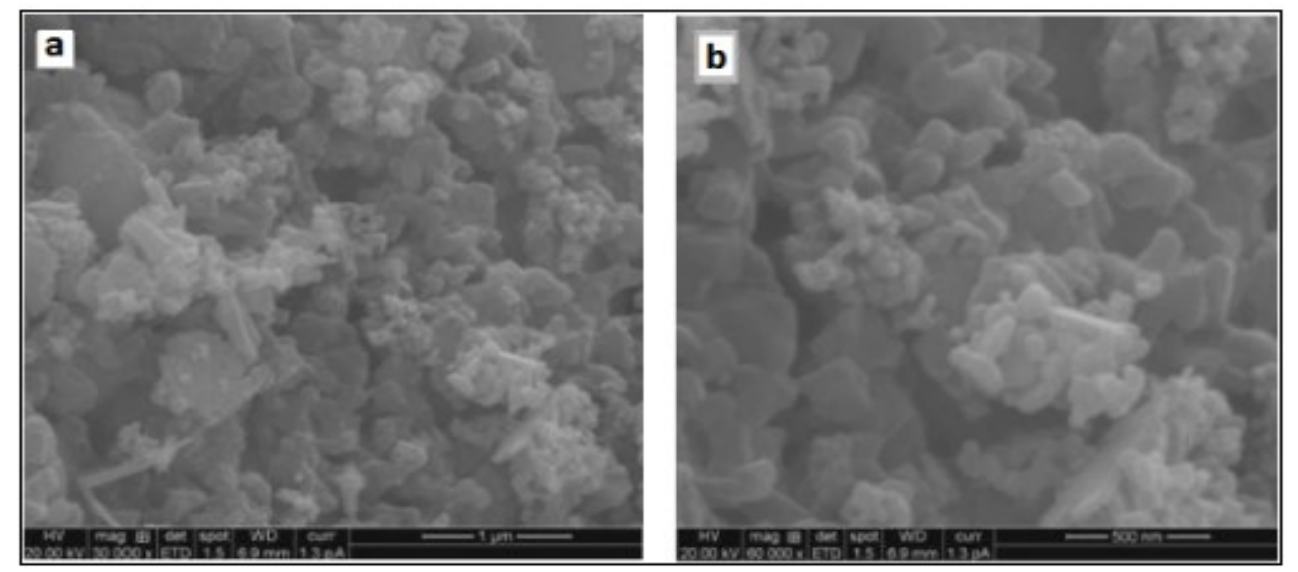

Fig.-3:(a) and (b) SEM Images of Copper Oxide Nanoparticles at Different Magnification

\section{Possible Mechanism of CuO Nanoparticles}

In rambutan peel extract, the active ingredients, polyphenolic compounds such as ellagic acid, corilagin and geranin are present as major components with high proportion. These natural phenolic antioxidant compounds have favorable effects for the synthesis of copper oxide nanoparticles and also have anti-carcinogenic in nature. ${ }^{38}$ Scheme 1 . shows the possible mechanism of copper oxide nanoparticles using rambutan peel extract. When a metal complex is formed in the initial step. Then 


\section{RASĀYAN J. Chem.}

Vol. 14 | No. 4 |2660-2665| October- December | 2021

after complexes undergo hydrolysis to precipitate metal ions as metal hydroxide or metal oxide, depending upon the reaction $\mathrm{pH}$, the $\mathrm{pH}$ value varies depending upon the metal ions. In our synthesis, rambutan peel extract permits the copper sulphate to precipitate the copper hydroxide at $\mathrm{pH} 5-7$. The precursor copper hydroxide undergoes calcining at $450^{\circ} \mathrm{C}$ yields copper oxide nanoparticles.

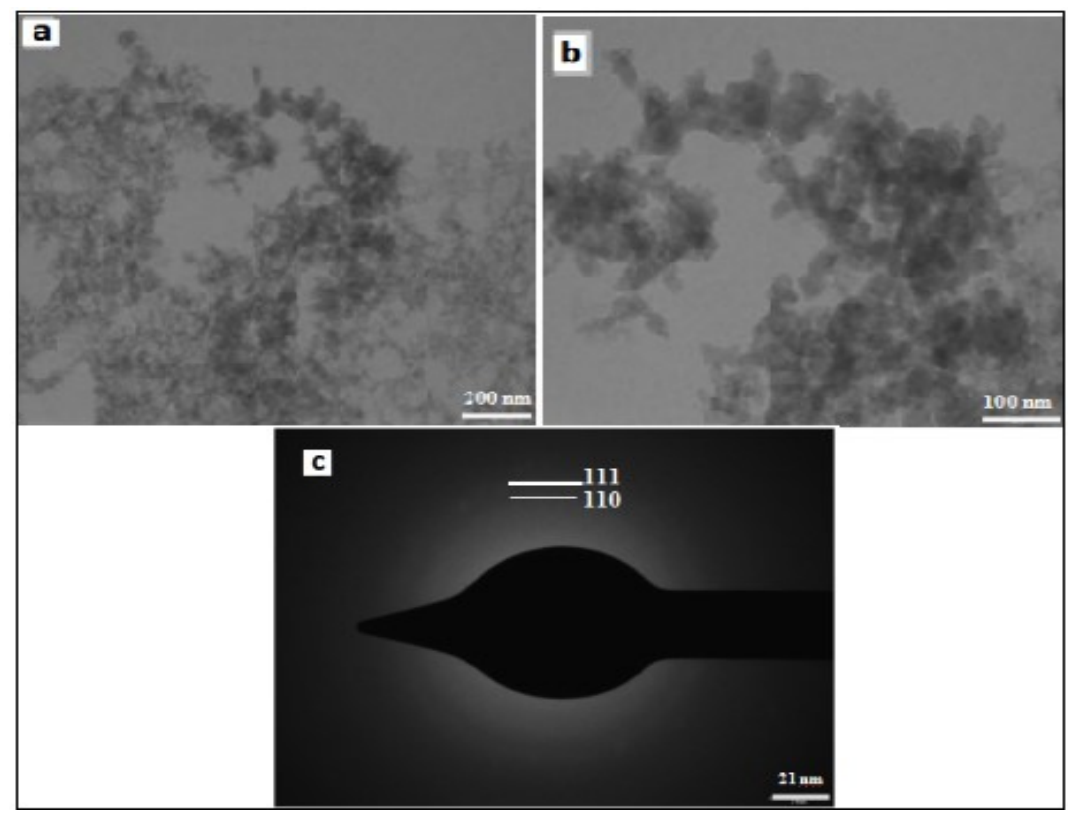

Fig.-4: TEM Images of Copper Oxide Nanoparticles (a \& b) and (c) SAED Pattern

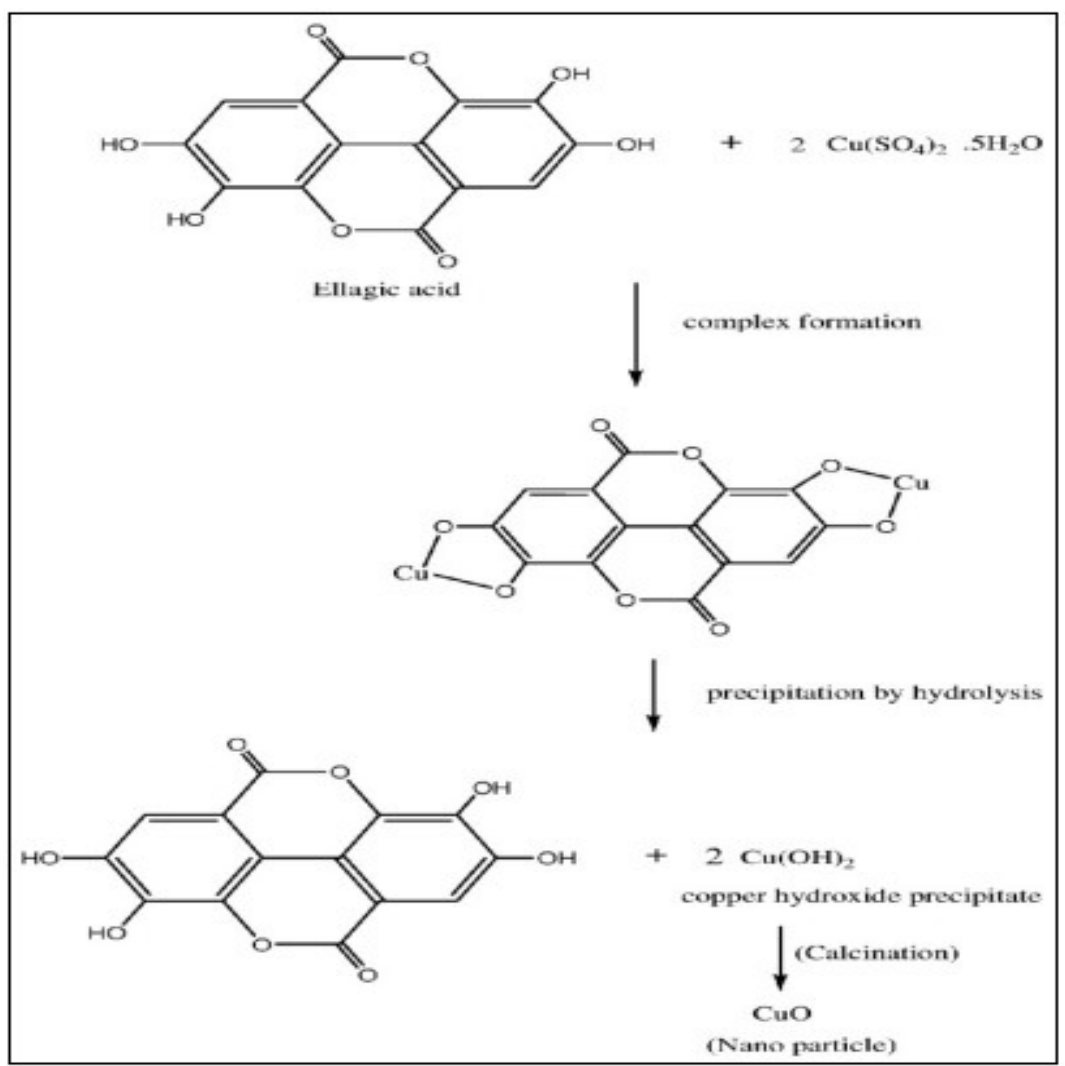

Scheme-1: Possible Mechanism of CuO Nanoparticle Formation using Rambutan Peel Extracts 
RASĀYAN J. Chem.

Vol. 14 | No. 4 |2660-2665| October- December | 2021

\section{CONCLUSION}

Copper oxide nanoparticles were synthesized using a simple, eco-friendly, inexpensive, greener route using rambutan peel extract. The synthesized nanoparticles were confirmed by UV Visible, XRD, SEM, TEM analysis. Further, we discussed the formation mechanism of copper oxide nanoparticles. More importantly, this present work can be extended to other metal oxide nanoparticles and this type of transition metal oxides have various more attention in biomedical applications.

\section{REFERENCES}

1. L. Wu, X. Cai, K. Nelson, W. Xing, J. Xia, R. Zhang, A. J. Stacy, M. Luderer, G. M. Lanza, L.V. Wang,. B. Shen, D. Pan, Nano Research, 6, 312 (2013), https://doi.org/10.1007/s12274-013-0308

2. G. Wang, F. Qian, C.W. Satikov, Y. Jiao Y. Li, Nano Research, 4, 563(2011), https://doi.org/10.1007/s12274-011-0112-2

3. S. Wenda, A. Illner, U. Mell Kragl, Green Chemistry, 13, 3007(2011), https://doi.org/10.1039/clgc15579b

4. S.P. Chandran, M. Chaudhary, R. Pasricha, A. Ahmad, M. Sastry, Biotechnology Progress, 22, 577 (2006), https://doi.org/10.1021/bp0501423

5. S. Philip, Physica E, 42, 1417 (2010), https://doi.org/10.1016/j.physe.2009.11.081

6. H. Liu, J. Huang, D. Sun, L. Lin, W. Lin, J. Li, X. Jiang, W. Wu, Q. Li, Chemical Engineering Journal, 209, 568 (2012), https://doi.org/10.1016/j.cej.2012.08.049

7. Y. Konishi, K. Ohno, N. Saitoh,T. Nomura, S. Nagamine, H. Hishida, Y. Takahashi, T. Uruga, Journal of Biotechnology, 128, 648 (2007), https://doi.org/10.1016/j.jbiotec.2006.11.014

8. W. Chen, L. Li, .Q. Peng, Y. Li, Nano Research, 5, 320 (2012), https://doi.org/10.1007/s12274-012$\underline{0212-7}$

9. J. Gabbay, E. Mishal, R. Magen,Y. Zatcoff, G. Shemer-Avni, Borkow, Journal of Industrial Textiles, 35, 323 (2006), https://doi.org/10.1177/1528083706060785

10. L. Jing, H. Jin, T. Xiaojian, Yiwei, Nano Research, 4(5), 448(2011), https://doi.org/10.1007/s12274-011-0101-5

11. B.G. Eranna, C. Joshi, D.P. Runthala, R. P. Gupta, Critical Reviews in Solid State and Materials Science, 29, 111(2004), https://doi.org/10.1080/10408430490888977

12. C.L. Carnes, K.J. Klabunde, Journal of Molecular Catalysis A:Chemical, 194, 227(2003), https://doi.org/10.1016/S1381-1169(02)00525-3

13. P.C. Dai, H.A. Mook, G. Aeppli, S.M. Hayden, F. Dogan, Nature, 406, 965(2000), https://doi.org/10.1038/35023094

14. A. Punnoose, A. Magnone, M.S. Seehra, Bonevich, Physical Review B, 64, 174420(2001), https://doi.org/10.1103/PhysRevB.69.054425

15. N. Serin, T. Serin, A. Horzum, Y.C. Elik, Semiconductor Science Technology, 20, 398(2005), https://doi.org/10.1088/0268-1242/20/5/012

16. H. Fan, L. Yang, W. Hua, X.F. Wu, Z. Wu, S. Xie, B. Zou, Nanotechnology, 15, 37(2004), https://doi.org/10.1088/0957-4484/15/1/007

17. R.V. Kumar, R. Elgamiel,Y. Diamant, A. Gedanken, J. Norwig, Langmuir, 17,1406 (2001), https://doi.org/10.1021/la001331s

18. K. Borgohain, J.B. Singh, M.V.R. Rama, T. Shripathi, S.Mahamuni, Physical Review B, 61, 11093( 2000), https://doi.org/10.1103/PhysRevB.61.11093

19. J.F. Xu, W. Ji, Z.X. Shen, S.H. Tang, X.R.Ye, D.Z. Jia, X.Q. Xin, Journal of Solid State Chemistry, 147, 516(1999), https://doi.org/10.1006/jssc.1999.8409

20. Z. H. Gan, G.Q. Yu, B. K. Tay, C. M. Tan, Z.W. Zhao, Y.Q. Fu, Journal of Physics D: Applied Physics, 37, 81(2004), https://doi.org/10.1088/0022-3727/37/7/013

21. M. Ghosh, C.N.R. Rao, Chemical Physics Letters, 393,493(2004), https://doi.org/10.1016/j.cplett.2004.06.092

22. M. Sastry, A. Ahmad, M.I. Khan, R. Kumar, C.M. Niemeyer, C.A. Mirkin, (Eds.), Wiley-VCH, 


\section{RASĀYAN J. Chem.}

Vol. 14 | No. 4 |2660-2665| October- December | 2021

Weinheim, Germany,126 (2004), https://doi.org/10.1002/3527602453.ch9

23.D. Bhattacharya, R.K. Gupta, Critical Reviews in Biotechnology, 25, 199(2005), https://doi.org/10.1080/07388550500361994

24. P. Mohanpuria, N.K. Rana, S.K. Yadav, Journal of Nanoparticle Ressearch, 10, 507(2008), http://dx.doi.org/10.1007/s11051-007-9275-x

25. A. Ahmad, S. Senapati, M.I. Khan, R. Kumar, M. Sastry, Langmuir, 19, 3550(2003), https://doi.org/10.1021/la0267721

26. J. Huang, C. Liu, D. Sun,Y. Hong, M. Du, T.O. Wubah, W. Fang, Q. Li, Chemical Engineering Journal, 235, 215 (2014), http://dx.doi.org/10.1016/j.cej.2013.09.035

27. S. Shiv Shankar, A. Ahmad, R. Pasricha, M. Sastry, Journal of Materials Chemistry, 13, 1822 (2003), https://doi.org/10.1039/B303808B

28. S. Hemalatha, M. Makeswari, Rasayan Journal of Chemistry, 10(3), 838(2017), http://dx.doi.org/10.7324/RJC.2017.1031800

29. S.C. Mali, S. Raj, R. Trivedi, Biochemistry and Biophysics Reports, 20,100699(2019) https://doi.org/10.1016/j.bbrep.2019.100699

30. D. Philip, Spectrochimica Acta Part A. 73, 374(2009), https://doi.org/10.1016/j.saa.2009.02.037

31. K.B. Narayanan, N. Sakthivel, Materials Letters, 62, 4588(2008), https://doi.org/10.1016/j.matlet.2008.08.044

32.D. Philip, Spectrochimica Acta A: Molecular Biomolecular Spectroscopy, 73, 650(2009), https://doi.org/10.1016/j.saa.2009.03.007

33. M. Gowri, N. Latha, M. Rajan, BioNanoScience, 9, 545 (2019), https://doi.org/10.1007/s12668-019$\underline{00655-7}$

34. K. Gopalu, J. Matheswaran, S.K. Govindan, K. Evgeny, The Journal of the Minerals, Metals \& Materials Society, 72,1264 (2020), https://doi.org/10.1007/s11837-020-04007-9

35. S.A. Moon, B.K. Salunke, P. Saha, A.R. Deshmukh, Korean Journal of Chemical Engineering, 35,702(2018), https://doi.org/10.1007/s11814-017-0318-4

36. N. Elavarasan, K. Kokila, S. Prakash, V. Sujatha, Journal of Cluster Sciemce, 30, 1157(2019), https://doi.org/10.1007/s10876-019-01579-8

37. A. Pramanik, A.K. Datta, D. Das, D.V. Kumbhakar, B. Ghosh, A. Mandal, S. Gupta, A. Saha, S. Sengupta, Cytology and Genetics, 4 (52), 299 (2018), http://dx.doi.org/10.3103/S0095452718040084

38. S.R. Przewloka, B.J. Shearer, Holzforschung, 56, 13(2002), https://doi.org/10.1515/HF.2002.003

[RJC-6512/2021] 